\title{
A Turkish BCS1L mutation causes GRACILE-like disorder
}

\author{
Esra Serdaroğlu ${ }^{1}$, Şahin Takc1 ${ }^{2}$, Heike Kotarsky ${ }^{3}$, Onur Çil ${ }^{1}$, Eda Utine ${ }^{1}$, Şule Yiğit ${ }^{1}$, \\ Vineta Fellman ${ }^{3,4}$ \\ ${ }^{1}$ Department of Pediatrics, Hacettepe University Faculty of Medicine, Ankara, ${ }^{2}$ Department of Pediatrics, Gaziosmanpasa \\ University Faculty of Medicine, Tokat, Turkey; ${ }^{3}$ Department of Pediatrics, Clinical Sciences, Lund University, Lund, Sweden; \\ ${ }^{4}$ Department of Pediatrics, Helsinki University Hospital and University of Helsinki, Helsinki, Finland. \\ E-mail: stakci@gmail.com
}

Received: 27th November 2014, Revised: 8th April 2015, Accepted: 19th April 2017

SUMMARY: Serdaroğlu E, Takcı Ş, Kotarsky H, Çil O, Utine E, Yiğit Ş, Fellman V. A Turkish BCS1L mutation causes GRACILE-like disorder. Turk J Pediatr 2016; 58: 658-661.

A full-term growth-restricted female newborn $(1790 \mathrm{~g})$, presented with lactic acidosis ( $12.5 \mathrm{mmol} / \mathrm{L})$ after birth. She had renal tubulopathy, cholestasis and elevated serum ferritin concentration $(2819 \mathrm{ng} / \mathrm{ml})$. Two similarly affected sisters had died before 3 months of age. Mitochondrial disorder was suspected since the disease resembled the Finnish GRACILE syndrome, caused by a homozygous mutation (c.232A>G) in BCS1L. Thus, we sequenced the BCS1L gene, encoding the assembly factor for respiratory chain complex III. The patient had a homozygous mutation (c.296C > T; p.P99L), for which both parents were heterozygous. In four previously published patients of Turkish origin, the same homozygous mutation resulted in complex III deficiency, tubulopathy, encephalopathy, and liver failure. The p.P99L mutation seems to be specific to Turkish population and leads to GRACILE-like or Leighlike condition. Assembly defects in complex III should be investigated in the affected tissues, since fibroblasts may not exhibit the deficiency.

Key words: GRACILE, BCS1L mutation, Turkish.

GRACILE syndrome (Fellman disease, MIM 603358) is a neonatal, autosomal recessive disorder, caused by a homozygous mutation (c.232A $>\mathrm{G}$ ) in BCS1L, which encodes the chaperone for the final assembly of respiratory chain complex III (cytochrome bc1 complex) by inserting the Rieske iron-sulfur subunit (RISP) into the pre-complex. The acronym GRACILE represents the main clinical characteristics: fetal Growth Restriction, Aminoaciduria due to proximal tubulopathy, Cholestasis, Iron overload, Lactic acidosis, and Early death ${ }^{1-3}$.

We report a Turkish newborn girl, who presented with clinical characteristics suggesting GRACILE syndrome. However, she did not have the typical Finnish mutation (p.S78G), but a homozygous mutation in an adjacent region, p.P99L, which previously was reported in four Turkish infants ${ }^{4-6}$.

\section{Case Report}

The 5-day old-girl was referred to neonatal intensive care unit from a rural area of Turkey. She was born at term to healthy non-consanguineous parents. She was growthrestricted (1790 g, <-2 SD), developed tachypnea and metabolic acidosis on the first day of life. Lactic acidosis (12.5 mmol/L), jaundice with increased conjugated bilirubin (total bilirubin $14.5 \mathrm{mg} / \mathrm{dl}$, conjugated 10.5 $\mathrm{mg} / \mathrm{dl}$ ), nonspecific aminoaciduria, excessive phosphaturia, proteinuria and glucosuria were detected. Serum iron $(190 \mathrm{mcg} / \mathrm{dl})$, ferritin $(2819 \mathrm{ng} / \mathrm{ml})$ and transferrin saturation (99.4\%) were increased. Metabolic, cardiologic and sonographic diagnostic work-up did not reveal any other abnormality. The infant died at 37 days of sequencing. Her two sisters born at term with a low birth weight (both $1850 \mathrm{~g})$, had metabolic acidosis $\left(\mathrm{pH} 7.1 \mathrm{HCO}_{3}\right.$ $8.7 \mathrm{mmol} / \mathrm{L}$ ), cholestasis and renal Fanconi syndrome, and died of the disorder at 18 and 90 days of age, respectively..

Because of similarities with GRACILE 
syndrome, the BCS1L gene was investigated at the Lund University, Lund Sweden. The Finnish GRACILE mutation (c.232A $>$ G) was not found. The gene sequencing (Fig. 1A) revealed a homozygous mutation (c.296C $>\mathrm{T}$ ) resulting in one amino acid exchange (p.P99L) in the protein. Both parents were heterozygous for this mutation. Pedigree of the investigated family including 3 generations is shown in Figure 1B.

Blue native gel electrophoresis was used to investigate $B C S 1 L$ and respiratory chain complexes in patient and control fibroblasts. Comparable levels of $B C S 1 L$ were identified in patient and control fibroblasts. Presence of complex III in mitochondrial membranes was similar in the patient as in controls, and RISP was present in the complex. The assembly of complex I, IV and II was similar in the patient and controls (Fig. 1C). The homozygous mutation causing one amino acid exchange is schematized in Figure 1D.

\section{Discussion}

GRACILE syndrome belongs to the "Finnish disease heritage," a group of rare hereditary diseases that are overrepresented in Finland due to the founder effect and genetic drift. More than 30 newborn infants of Finnish ancestors have been diagnosed with the disorder (Table 1) and all had the same homozygous point mutation in exon 2 (c.232A $>\mathrm{G}$ ) resulting in one amino acid exchange (Serine to Glycine, p.S78G) in the protein ${ }^{1}$. The patients are severely growth restricted from fetal life with a birth weight of -4 SD. Fulminant lactic acidosis develops on the first day of life and is resistant to treatment. Iron overload presents with hemosiderosis of liver, increased serum ferritin concentration, hypotransferrinemia with increased transferrin saturation and free plasma iron $^{3}$. Brain involvement and dysmorphic features have not been found.

The human BCS1L gene homologue was first identified in yeast $S$. cerevisiae as bcs1. Thus, yeast studies have elucidated the role of the protein and deficiencies caused by specific mutations in $i^{5}$. The protein acts as ATP dependent chaperone in the assembly of complex III, which catalyzes electron transfer from ubiquinol to cytochrome $\mathrm{C}$. In yeast, mutations in the protein cause lack of RISP in complex III resulting in decreased complex activity. In human mutations, similar deficiencies are found in diseased tissues ${ }^{3-5}$, but not necessary in fibroblasts ${ }^{2}$. In fibroblasts of our patient, we could not show an assembly defect like the findings in fibroblasts of GRACILE infants, in whom the target organ is liver ${ }^{2}$.

In humans, more than 20 mutations have been identified, and an increasing number of patients have been described with variable severity ranging from mild congenital neurosensory hearing loss and distorted hair, the hallmarks of Björnstads syndrome to tubulopathy alone, or combined with hepatopathy with some iron
A

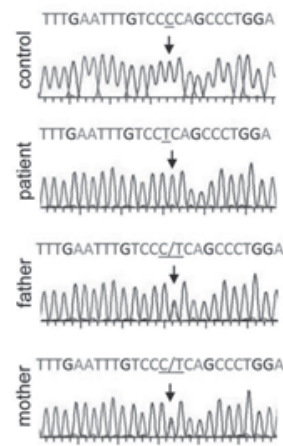

B

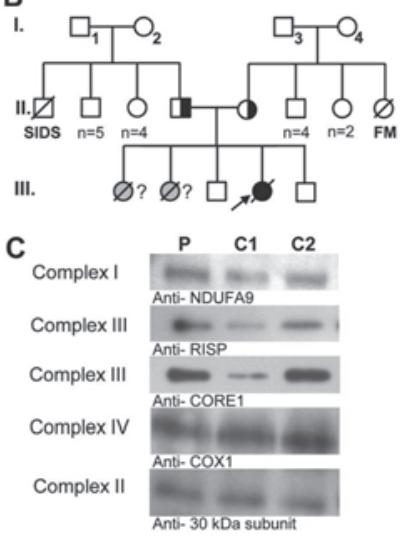

D

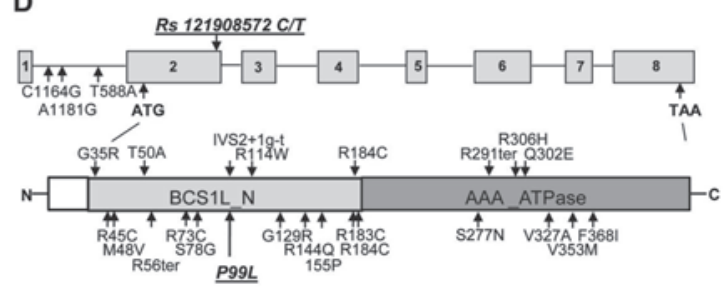

Figure. A. The part of BCS1L sequence showing the homozygous mutation in the patient and heterozygosity in parents, indicated with arrows. B. Pedigree of the investigated family showing 3 generations. Deceased individuals are marked with a diagonal line, the homozygous patient with an arrow. Her siblings, most likely also homozygous, are marked in grey. The grandparents lived in adjacent areas, the distance between 1 and 2 was 47 $\mathrm{km}$ and between 2 and 3 was $100 \mathrm{~km}$. SIDS, sudden infant death syndrome, FM, fetus mortus. C. Fibroblasts were investigated by blue native gel electrophoresis showing similar amount of complexes I, III, IV and II in the patient and control infants. Despite the BCS1L mutation, Rieske subunit (RISP) was assembled into complex III. Antibodies were used against subunit NDUFA9 for complex I, RISP and Core1 for complex III, COX1 and $30 \mathrm{kDa}$ subunit, respectively for complexes IV and II. D. Cartoon of the BCS1L gene consisting of 8 exons with the mutation indicated in exon 2 and the corresponding amino acid exchange P99L shown in the protein. Other known mutations in the gene are indicated, the majority of them are located in the BCS1L specific domain. 
Table I. GRACILE Syndrome Characteristics ${ }^{3}$ Compared to Our Case and Previous Patients ${ }^{4-6}$

\begin{tabular}{|c|c|c|c|}
\hline & $\begin{array}{l}\text { Finnish patients } \\
(\mathrm{S} 78 \mathrm{G})(\mathrm{n}=24)\end{array}$ & $\begin{array}{l}\text { Our patient } \\
\text { (P99L) }\end{array}$ & $\begin{array}{l}\text { Previous patients } \\
\text { (P99L) }(\mathrm{n}=4)\end{array}$ \\
\hline Male/Female, $\mathrm{N}$ & $10 / 24$ & Female & $1 / 3$ \\
\hline Gestational age, weeks & $37.9(36.3-39.2)$ & Term & All term \\
\hline Birth weight, g & $\begin{array}{c}1715 \\
(1465-1870)\end{array}$ & 1790 & $2340,2620,<3 \%, 2070$ \\
\hline $\begin{array}{l}\text { Metabolic acidosis } \\
\text { pH } \\
\text { Base excess } \\
\text { Lactate, mmol/L }\end{array}$ & $\begin{array}{c}7.02(6.95-7.10) \\
-22(-25--20) \\
12.8(7.6-20)\end{array}$ & $\begin{array}{l}6.9 \\
-26 \\
12.5\end{array}$ & $\begin{array}{c}\text { 7.25, ND, ND, } 7.25 \\
-,-12 \\
8,22,6.8,62\end{array}$ \\
\hline Ferritin, $\mathrm{ng} / \mathrm{ml}$ & $1260(980-1700)$ & 2819 & ND, ND, Ý, 2000 \\
\hline $\begin{array}{l}\text { Increased transferrin } \\
\text { saturation }\end{array}$ & + & + & $\mathrm{ND}, \mathrm{ND},+, \mathrm{ND}$ \\
\hline $\begin{array}{l}\text { Proximal tubulopathy } \\
\text { Liver disorder } \\
\text { High transaminases } \\
\text { Iron accumulation }\end{array}$ & $\begin{array}{l}+ \\
+ \\
+ \\
+\end{array}$ & $\begin{array}{l}+ \\
+ \\
+ \\
?\end{array}$ & $\begin{array}{l}+,+,+,+ \\
+,+,+,+ \\
+,+,+,+ \\
\text { ?, ?, ?, ? }\end{array}$ \\
\hline $\begin{array}{l}\text { CNS symptoms } \\
\text { Hypotonia } \\
\text { Leigh syndrome }\end{array}$ & - - (none) & $\begin{array}{l}- \\
-\end{array}$ & $\begin{array}{l}+,+,+,+ \\
+,+,-,-\end{array}$ \\
\hline $\begin{array}{l}\text { Complex III } \\
\text { Assembly defect }\end{array}$ & $\begin{array}{l}\text { Liver + } \\
\text { Fibroblast - }\end{array}$ & $\begin{array}{l}\text { Liver ND } \\
\text { Fibroblast - }\end{array}$ & $\begin{array}{c}\text { Liver ND } \\
\text { Fibroblast: ND,ND,ND }\end{array}$ \\
\hline $\begin{array}{l}\text { Decreased activity } \\
\text { Age at death }\end{array}$ & $\begin{array}{ll} & \text { Liver }+ \\
31 & (2-63) \text { days }\end{array}$ & $\begin{array}{l}\text { ND } \\
37 \text { days }\end{array}$ & $\begin{array}{l}+,+,+{ }^{*}, \text { ND } \\
6,24,7,9 \text { months }\end{array}$ \\
\hline
\end{tabular}

Values given as median (IQR) or individual ones; ND: not determined; + :present; - :absent; ? :not known

*: fibroblast in case 1,3 , liver in case 2

accumulation and/or encephalopathy ${ }^{2}$. Whether this variability can be linked to a secondary function of $B C S 1 L$ is unclear, but possible since other AAA-proteins have dual functions. In a study on patients with proven complex III deficiencies, two infants of Turkish origin from unrelated consanguineous families (Table 1) had the same p.P99L mutation as our patient (Fig. $1 \mathrm{~A})^{4}$. In another study, one Turkish patient was reported with the same mutation and similar clinical features as in GRACILE syndrome (Table 1$)^{5}$. Also in a recent study from Turkey, an infant with hypotonia, metabolic acidosis and severe tubulopathy with homozygous p.99L in BCS1L gene has been described. This infant and our patient were coming from neighboring provinces in Turkey ${ }^{6}$. These four infants and our patient with verified p.P99L mutation, and further her two siblings with similar disorder, but not genotyped, suggest that this specific mutation is represented in Turkish patients. Interestingly, the phenotype varies with some infants surviving for months, even up to two years (Table 1). This suggests that other factors may interact on the severity of hepatopathy, which we believe is resulting in energy depletion and a fasting state related death. In those who survive, it seems that a neurologic disorder may develop over time ${ }^{5}$.

The presented infant had a GRACILE-like disorder caused by a different mutation than that in newborns of Finnish ancestors. Most likely the two affected siblings of the patient had the same homozygous BCS1L mutation that previously has been published in three other newborns of Turkish origin. We propose 
that this mutation in $B C S 1 L$ causing p.P99L is a Turkish genotype resulting in a GRACILElike syndrome, and should be investigated in Turkish newborns with the typical features of the syndrome.

\section{Acknowledgements}

We are grateful to technician Eva Hansson who sequenced the gene.

Ethics: Lund University Regional Ethics Committee, Lund, Sweden.

\section{REFERENCES}

1. Fellman V, Lemmela S, Sajantila A, Pihko H, Järvelä I. Screening of BCS1L mutations in severe neonatal disorders suspicious for mitochondrial cause. J Hum Genet 2008; 53: 554-558.

2. Kotarsky H, Karikoski R, Mörgelin M, et al. Characterization of complex III deficiency and liver dysfunction in GRACILE syndrome caused by a BCS1L mutation. Mitochondrion 2010; 10: 497-509.
3. Visapaa I, Fellman V, Vesa J, et al. GRACILE syndrome, a lethal metabolic disorder with iron overload, is caused by a point mutation in BCS1L. Am J Hum Genet 2002; 71: 863-876.

4. de Lonlay P, Valnot I, Barrientos A, et al. A mutant mitochondrial respiratory chain assembly protein causes complex III deficiency in patients with tubulopathy, encephalopathy and liver failure. Nat Genet 2001; 29: 57-60.

5. Moran M, Marin-Buera L, Gil-Borlado MC, et al. Cellular pathophysiological consequences of BCS1L mutations in mitochondrial complex III enzyme deficiency. Hum Mutat 2010; 31: 930-941.

6. Ezgu F, Senaca S, Gunduz M, et al. Severe renal tubulopathy in a newborn due to BCS1L gene mutation: effects of different treatment modalities on the clinical course. Gene 2013; 528: 364-366. 